\title{
Identification determinant factors on willingness to pay for health services in Iran
}

\author{
Javad Javan-Noughabi ${ }^{1,2}$, Zahra Kavosi ${ }^{3}$, Ahmad Faramarzi ${ }^{4}$ and Mohammad Khammarnia ${ }^{5^{*}}$
}

\begin{abstract}
Background: A common method used to examine the relationship between internal preferences and caring externalities is willingness to pay (WTP) approach. We aimed to estimate WTP for health status with different severity level and identify determinant factors on WTP.

Methods: For determining main factors in WTP, a cross-sectional study was conducted in Shiraz in the southeast of Iran, in March to April 2015. The open-ended method was used to estimate monthly WTP in private and altruistic section. Multivariate regression analyses using ordinary least squares were applied to examine the effect of Scio-demographic factors on WTP using SPSS software 21.

Results: Participants were willing to pay an average amount of $\$ 295$ in health status 1 and an average amount of \$596 in health status 6 (worst status) for internal preferences. Altruistic WTP for health status 1 was $\$ 294$ and participants were willing to pay an average amount of $\$ 416$ in health status 6 . Multiple regression analysis identified monthly income as the key determinant of WTP for internal preferences and caring externalities $(P<0.01)$. With an increase of $1 \%$ in income, private WTP increase $1.38 \%$ in health status 1.

Conclusions: The finding indicates that the mean of WTP increases at severe health status; therefore, health policy maker should allocate resources toward severe health status.
\end{abstract}

Keywords: Willingness to pay, Altruistic, Private, Iran

\section{Background}

Many economists believe that healthcare is different in ways that generate market failure, therefore it is important for formulating public policy in the health sector [1-3]. externalities is one of the most discussed in health market failure, an external effect is existed when benefits and costs of an activity by some agent accrue to someone not directly involved in the activity, and this effect is not prized by the market [4].

In the economic evaluation are existed some procedures for measuring of caring externalities that one approach is altruistic willingness to pay (WTP). Auguste Comte first time used the concept of altruism and believed that there are two separate forces or motivation in every human, one of them focused on their own interests that are selfishness and other force focused on others and the interests of others that is altruism [5].

\footnotetext{
* Correspondence: m_khammar1985@yahoo.com

${ }^{5}$ Health Promotion Research Center, Zahedan University of Medical Sciences,

Zahedan, Iran

Full list of author information is available at the end of the article
}

WTP is the maximum amount of income an individual is willing to give up to ensure that a proposed service or good is available [6].

In the health sector, various studies have been estimated WTP with different methods for health services. For instance, Wang et al. (2015) done study on the Impacts of Healthy Eating and Anti-Obesity Advertising on Willingness-to-Pay by Consumer Body Mass Index $[7,8]$. X Yu et al. (2014) estimated WTP for the "Green Food" in China [9] Dror found that using bidding game among 3024 households at the rural location in India, about two-third of sample agree to WTP for health insurance [10]. Basu (2013) applied contingent valuation approach to estimate willingness to pay for prevent Alzheimer's disease and demonstrated the mean of WTP is $\$ 155$ per month [11].

Open - ended is an approach which is used for the measurement of WTP, in this approach as respondent is asked, "How much would you be willing to pay to be cured?" [12] this approach has been frequently used in 
the economic evaluation [13-17]. For example, Li et al. (2017) used open-ended format to estimate to WTP for newborn screening test for spinal muscular atrophy which their study showed that People expressed a willingness to pay for spinal muscular atrophy screening even without an available therapy (median: \$142; mean: $\$ 253)$. Willingness to pay increased with treatment availability and respondent income $[18,19]$.

The relationship between caring externalities and internal preferences (altruistic WTP and private WTP) for health status with different severity levels and determinant factors on WTP were studied as the purpose of the current research. The results of the study could be helpful for health policy makers and mangers in accurate planning in health system.

\section{Methods}

\section{Setting and sample}

A cross-sectional study was conducted among adults that have income from the general population in Shiraz, Iran, in March to April 2015. Shiraz is the center of health care and medical tourism in Iran and is located in the southeast of Iran [20]. The design of the study was explorative; therefore, it was important to obtain the views of different social groups. By that, the participants were selected from different settings. The sample size was determined using the following equation in which $p=0.8$, and $\mathrm{d}=0.055[21]$.

$$
N=\frac{Z_{1-\frac{a}{2}(1-p)}}{d^{2}}=200
$$

For sampling, the population was divided into 9 areas then on average 25 participants was randomly selected of each region.

The used scenarios in the study was based on that participants do not have insurance to pay for different status or services are not free, in addition health status were independent from each other. Data collection was conducted by open-ended questionnaire in a face-to-face interview. To recognize of external factors that might influence on WTP in this study, the participants were asked to provide their sex, educational background, employment status, and income per month. In other parts of the questionnaire, it was possible to compare private WTP and altruistic WTP.

\section{Data collection tool}

Data was collected by questionnaire, which had included two parts; the first part was included demographic variable (sex, educational background, employment status and income per month). In other part, the questionnaire asked from participants to declare private WTP and altruistic WTP in six level of health status. Six levels regarding mobility(physical activity) were used from a scale constructed by Nord [22]; which included: first, can move about without difficulty anywhere, but has difficulties with walking more than a kilometre. Second, can move about with difficulty at home, but has difficulties in stairs and outdoors. Third, moves about with difficulty at home, needs assistance in stairs and outdoors. Fourth, can sit, needs assistance to move about both at home and outdoors. Fifth, to some degree bedridden can sit on a chair in part of the day if helped up by others and sixth, completely bedridden.

\section{WTP measurement}

There are four ways to measure WTP in economic evaluation: open-ended, take-it-or-leave-it (or alternatively discrete choice), payment card, and bidding games types of questions [23, 24]. We chose the open-ended method for this study, this method has previously been used in many studies, in addition there is little information for altruistic and private willingness to pay in health care and the open-ended technique is a good method for obtaining first estimates $[25,26]$.

We applied private WTP and altruistic WTP for evaluation internal preferences and caring externalities. To estimate private WTP, the question dealt with the health status of participants and was asked as respondent in current way: "If you are suffering from the different health status. How much are you willing to pay to be cured from each health state?"

The scenarios were used to estimate the altruistic WTP the same as in private WTP, but the question relates to others health status and was asked as participants in following way: "suppose a stranger person suffers as described health status and you don't know exactly who she/ he is, but he/she cannot be treated due to inability to pay medical expenses. How much are you willing to pay for her/him treatment of any health status?"

\section{Data analysis}

Data was analysed on STATA 13 version. The data analysis was started with descriptive analysis (frequency and mean) which would allow us to explore the data and identify specific trend of the study's variables. In the descriptive phase of the study, private WTP compared to altruistic WTP. In addition, since data in private WTP had non-normal distribution; therefore, logarithm was used for analysis while there was no need to get Logs for altruistic WTP data. Moreover, to test the effect of explanatory variables on private WTP and altruistic WTP was applied of OLS regression in each health status.

The below model was performed in analysis: 


$$
Y_{i}=\alpha+\beta_{1} X_{1 i}+\beta_{2} X_{2 i}+\ldots .+e_{i} \quad i=1 \ldots \ldots n
$$

Where $Y_{\mathrm{i}}$ denotes natural logged private WTP; however, for altruistic WTP is dollar (\$), $\alpha$ is a constant, $\mathrm{X}_{\mathrm{i}}$ denotes the control variables, $\beta$ represents the coefficient and e is an error term.

- Ethics approval and consent to participate:

This study was approved by Ethic Committee of Shiraz University of Medical Sciences.

\section{Results}

Scio-demographic characteristics of the study population A total of 200 participants take part in this study. More than $60 \%$ of them have academics education. Furthermore, more than of $50 \%$ of participants were male. (See Table 1).

According to the results, about $88.8 \%$ of the participants were willing to pay for health status. The study results showed that the mean of participants' income was US\$ 707. They were willing to pay an average amount of \$ 295 in health status 1 and an average amount of \$ 596 in health status 6 (worst status) for internal preferences. Moreover, altruistic WTP for health status 1 was \$294 and participants were willing to pay an average amount of $\$ 416$ in health status 6 .

According to Table 1, the mean of monthly income was significant for gender and education $(P=0.001$ and $P=0.001$, respectively.). So male participants had higher income rather than females and persons with academic education had higher income rather than others. Table 1 shows monthly income for participant regarding to demographic variables.

Private WTP compare to altruistic WTP for different health status are shown in Fig. 1. Based on the Figure, the mean value of private WTP is higher than the mean value of the altruistic WTP in all health status and difference in the WTP is higher in the sever status. This means that, the mean value of private WTP for owns improvement from first and last health status were $\$$ 295 and \$ 596 respectively. But, Altruistic WTP for

Table 1 The average monthly income of participants regarding to demographics variables

\begin{tabular}{lllll}
\hline Variables & & Frequency (\%) & $\begin{array}{l}\text { Month mean } \\
\text { (USA \$) }\end{array}$ & P value \\
\hline Sex & Male & $111(55.5)$ & 866 & 0.001 \\
& Female & $89(44.5)$ & 508.5 & \\
Age & $<35$ & $112(56.0)$ & 667 & 0.112 \\
& $\geq 35$ & $88(44.0)$ & 759 & 0.201 \\
Marital Status & Single & $93(46.5)$ & 748 & 0.001 \\
& Married & $107(53.5)$ & 670.5 & \\
Education & non-academics & $66(33.0)$ & 519.5 & 799.5 \\
& academics & $134(67.0)$ & & \\
\hline
\end{tabular}

others health improvement from first and sixth health status were \$ 294 and \$ 416 respectively. This demonstrates that the respondents had understood the different scenarios.

Table 2 shows determinant factors on private WTP in different status of health. For example, model 1 shows the effect of studied variables on the private WTP for first health status that explanted in the method. Regression analysis showed that among the studied variables only monthly income of participant had significantly influenced on private WTP in all different status of health in significant level of 0.01 . For instance, in first health status, the increase of $1 \%$ of the monthly income results in $1.3 \%$ increase in the private WTP. Moreover, in significant level of 0.01 , sex had significant effect on private WTP for first and second health status (Model one and two).According to Table 2, in significant level of 0.05 , only education status had significant effect on private WTP for fourth health status (Model four).

Table 3 shows determinants factors that effect on the person's WTP who tendency to pay for other's health improvement (altruistic WTP). Regression analysis in Table 3 showed that monthly income of respondents significantly influenced on altruistic WTP in all different status of health $(P<0.01)$. For example, in first health status (Model one), the increase of $1 \%$ of the monthly income results in \$ 251 increase in the altruistic WTP. Also, in significant level of 0.01 , sex in model two, three and four had statistically significant on altruistic WTP. Moreover, in significant level of 0.05 , sex had significant effect on altruistic WTP for first and fifth health status (Model one and five).

\section{Discussion}

The study was designed to determine important factors which are effective on private and altruistic WTP in Iran. We found that a large proportion of participants had willing to pay for one's own (private WTP) and for others' (altruistic WTP) hypothetical health improvement. Moreover, amount of private WTP and altruistic WTP increases with worsening health status; however, in all of health status the value of private WTP was higher than value of altruistic WTP and the difference becomes further in the severity health status. A similar study conducted by Jacobsson in Sweden found that the mean value of private WTP and altruistic WTP for sixth health status were $\$ 1000$ and $\$ 8000$ respectively, which were higher than from our study [27]. The difference of WTP in our study compared to Jacobsson could be several reasons. First, the study was conducted in countries that are different as culturally, so the willingness to pay is usually lower in developing countries, for example, the average of WTP for health insurance in the USA in 2008 was 75 to \$125; however, this amount was \$ 47 in 


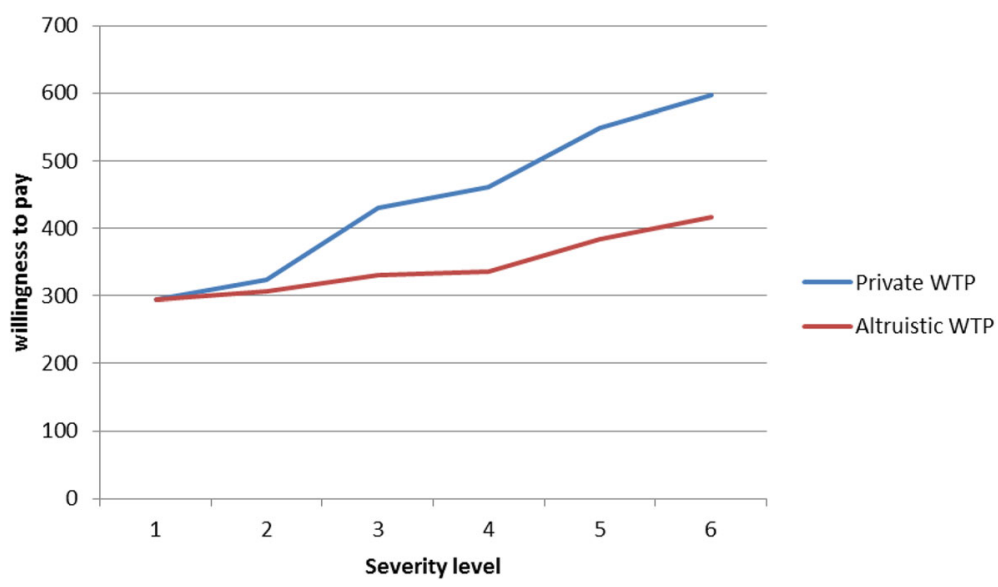

Fig. 1 The mean of private and altruistic WTP in the southwest of Iran

Namibia [28, 29]. Second, Jacobsson's study was conducted in 2001, so it could be discounted the timevalue of money. According to the formula of the discount rate, the value of money has been decreased over time [30, 31].

Our results have indicated income is an important predictor for willingness to pay. If income increases $1 \%$, private WTP will be increased $1.38 \%$ and $1.02 \%$ in health status 1 and 6, respectively. Moreover, with an increase of $1 \%$ of income, the altruistic WTP is increased \$ 251 and $\$ 292$ in health status 1 and 6, respectively. In line with the study's findings, Ahmed et al. 2015, Wright et al. 2009, Krupnick et al. 2002, also observed significant association between WTP and income [28, 32, 33].
Our analysis was explained that none of demographic variables has significant relationship with WTP for different health status however, gender, for example in the health status 1 the value of private WTP for women is higher than men but the amount of altruistic WTP for men is higher. There are no similar previous studies which confirm our results.

There are some limitations of the present study that need to be considered. One potential limitation of open-ended methods is related to bias that participants express the value of WTP incorrectly. Second, it is possible that respondent don't understand which scenarios are independent from each other, so WTP for each strategy was related to other scenarios. Third, it is

Table 2 Ordinary least square regression for private WTP (Log) in different health status

\begin{tabular}{|c|c|c|c|c|c|c|}
\hline \multirow[t]{2}{*}{ Variables } & Model 1 & Model 2 & Model 3 & Model 4 & Model 5 & Model 6 \\
\hline & WTP (SE) & WTP (SE) & WTP (SE) & WTP (SE) & WTP (SE) & WTP (SE) \\
\hline \multirow[t]{2}{*}{ Cons } & $-8.07^{b}$ & $-5.85^{b}$ & $-2.59^{b}$ & $-1.94^{b}$ & $-1.31^{b}$ & -.53 \\
\hline & $(0.82)$ & $(0.75)$ & $(0.56)$ & $(0.65)$ & $(0.40)$ & $(0.45)$ \\
\hline \multirow[t]{2}{*}{ Sex (ref = male) } & $0.21^{\mathrm{b}}$ & $0.16^{\mathrm{b}}$ & 0.07 & 0.07 & 0.01 & -0.03 \\
\hline & $(0.06)$ & $(0.05)$ & $(0.04)$ & $(0.04)$ & $(0.03)$ & $(0.03)$ \\
\hline \multirow[t]{2}{*}{ Age (ref $=$ less than 35 year) } & 0.04 & 0.01 & -0.007 & 0.01 & -0.03 & 0.01 \\
\hline & $(0.06)$ & $(0.05)$ & $(0.04)$ & $(0.04)$ & $(0.03)$ & $(0.03)$ \\
\hline \multirow[t]{2}{*}{ Marital status (ref = single) } & 0.10 & 0.09 & 0.02 & 0.02 & 0.004 & -.03 \\
\hline & $(0.06)$ & $(0.05)$ & $(0.04)$ & $(0.04)$ & $(0.03)$ & $(0.03)$ \\
\hline \multirow[t]{2}{*}{ Education (ref = nonacademic) } & 0.02 & 0.02 & 0.05 & $0.11^{\mathrm{a}}$ & 0.04 & -0.02 \\
\hline & $(0.06)$ & $(0.05)$ & $(0.04)$ & $(0.05)$ & $(0.03)$ & $(0.03)$ \\
\hline \multirow[t]{2}{*}{ Income } & $1.38^{\mathrm{b}}$ & $1.27^{\mathrm{b}}$ & $1.1^{\mathrm{b}}$ & $1.06^{\mathrm{b}}$ & $1.05^{\mathrm{b}}$ & $1.02^{b}$ \\
\hline & $(0.04)$ & $(0.04)$ & $(0.03)$ & $(0.03)$ & $(0.02)$ & $(0.02)$ \\
\hline R square & 0.82 & 0.83 & 0.87 & 0.82 & 0.92 & 0.90 \\
\hline
\end{tabular}

${ }^{a}$ Significant level at 0.05

${ }^{\mathrm{b}}$ Significant level at 0.01 
Table 3 Ordinary least square regression for altruistic WTP in different health status

\begin{tabular}{|c|c|c|c|c|c|c|}
\hline & Model 1 & Model 2 & Model 3 & Model 4 & Model 4 & Model 4 \\
\hline & WTP (SE) & WTP (SE) & WTP (SE) & WTP (SE) & WTP (SE) & WTP (SE) \\
\hline \multirow[t]{2}{*}{ Cons } & $-1330.26^{b}$ & $-1274.28^{b}$ & $-1311^{b}$ & $-1245.95^{b}$ & $-1341.48^{\mathrm{b}}$ & $-1314.88^{b}$ \\
\hline & $(115.69)$ & $(112.04)$ & $(106.55)$ & $(111.79)$ & $(210.38)$ & (337.53) \\
\hline \multirow[t]{2}{*}{ Sex (ref = male) } & $-48.12^{a}$ & $-58.22^{b}$ & $-58.38^{\mathrm{b}}$ & $-60.29^{b}$ & $-85.53^{\mathrm{a}}$ & -102.45 \\
\hline & $(19.71)$ & (19.09) & $(18.15)$ & $(19.04)$ & $(35.84)$ & $(57.5)$ \\
\hline \multirow[t]{2}{*}{ Age (ref $=$ less than 35 year) } & 27.08 & 25.9 & 33.17 & 26.81 & -23.99 & 1.36 \\
\hline & $(20.06)$ & $(19.43)$ & $(18.48)$ & (19.39) & $(36.49)$ & $(58.54)$ \\
\hline \multirow[t]{2}{*}{ Marital status (ref = single) } & 35.17 & 32.9 & 28.31 & 25.98 & 67.98 & -15.53 \\
\hline & $(19.49)$ & (18.88) & $(17.95)$ & $(18.83)$ & $(35.45)$ & $(56.87)$ \\
\hline \multirow[t]{2}{*}{ Education (ref = nonacademic) } & 1.93 & 3.7 & 4.97 & 2.91 & 16.95 & 23.13 \\
\hline & $(20.24)$ & (19.6) & (18.64) & (19.56) & (36.81) & (59.06) \\
\hline \multirow[t]{2}{*}{ Income } & $251.1^{\mathrm{b}}$ & $246.76^{b}$ & $255.65^{b}$ & $249.30^{b}$ & $274.76^{b}$ & $292.54^{b}$ \\
\hline & $(15.41)$ & (14.92) & (14.19) & $(14.89)$ & (28.02) & $(44.95)$ \\
\hline R square & 0.65 & 0.66 & 0.7 & 0.67 & 0.42 & 0.24 \\
\hline
\end{tabular}

${ }^{\mathrm{a}}$ Significant level at 0.05

${ }^{\mathrm{b}}$ Significant level at 0.01

difficult to disclose the real income of the participants; in particular the study was designed at the individual level and cross sectional.

\section{Conclusions}

This current study is provided evidence on WTP for health status and demonstrated that a large proportion of participants had WTP for health status. The value of WTP was difference for internal preference and caring externalities. This study indicates that the mean of WTP increases at severe health status, therefore health policy maker should allocate resources toward severe health status. Among the Scio-economics and demographic factors only income and gender was associated with the WTP significantly.

\section{Acknowledgements}

We would to thanks from any participants who contributed in the study. This study was supported by Shiraz University of Medical Science. Also, we would like to thanks from Samin Nobakht who contributed in data collection in the study.

\section{Funding}

This study was supported by Shiraz University of Medical Science (grant no. 92-01-21-7009).

\section{Availability of data and materials}

'Not applicable.

\section{Authors' contributions}

All authors contributed equally. All authors read and approved the final manuscript.

\section{Ethics approval and consent to participate}

This study was approved by Ethic Committee of Shiraz University of Medical Sciences.

\section{Consent for publication}

The Ethic Committee of Shiraz University of Medical Sciences confirmed the publication of the manuscript.

\section{Competing interests}

The authors declare that they have no competing interests.

\section{Publisher's Note}

Springer Nature remains neutral with regard to jurisdictional claims in published maps and institutional affiliations.

\section{Author details}

${ }^{1}$ Health Management and Economics Research Center, Iran University of Medical Sciences, Tehran, Iran. ${ }^{2}$ Department of Health Economics, School of Health Management and Information Sciences, Iran University of Medical Sciences, Tehran, Iran. ${ }^{3}$ Health Human Resources Research Center, Shiraz University of Medical Sciences, Shiraz, Iran. ${ }^{4}$ Department of Health Management and Economics, School of Public Health, Tehran University of Medical Sciences, Tehran, Iran. ${ }^{5}$ Health Promotion Research Center, Zahedan University of Medical Sciences, Zahedan, Iran.

Received: 30 June 2017 Accepted: 9 November 2017

Published online: 21 November 2017

\section{References}

1. Wong LY. Development of a holistic internet marketing strategy framework (IMSF) in promoting medical tourism industry (MTI) in Malaysia: Universiti Tun Hussein Onn Malaysia; 2016.

2. Durham J, Blondell SJ. Research protocol: a realist synthesis of cross-border patient mobility from low-income and middle-income countries. BMJ Open. 2014;4(11):e006514.

3. Culyer AJ, Newhouse JP. Handbook of health economics: Elsevier; 2000.

4. Briggs A. Sugar tax could sweeten a market failure: Britain has announced a tax on sugary drinks. Countries should go further and target foods that have large carbon footprints, says Adam Briggs. Nature. 2016;531(7596):551-2.

5. Campbell RL. Reply to Robert H. Bass," egoism versus rights"(spring 2006): altruism in Auguste Comte and Ayn Rand. The Journal of Ayn Rand Studies. 2006;7(2):357-69.

6. Mbachu C, Okoli C, Onwujekwe O, Enabulele F. Willingness to pay for antiretroviral drugs among HIV and AIDS clients in south-east Nigeria. Health Expect. 2017;00:1-9. doi:org/10.1111/hex.12612 
7. Wang R, Liaukonyte J, Kaiser HM. Does advertising content matter? Impacts of healthy eating and anti-obesity advertising on willingness-to-pay by consumer body mass index. J Agric Resour Econ. 2015;8:1-41.

8. Green $\mathrm{CH}$, Tunstall $\mathrm{SM}$. The evaluation of river water quality improvements by the contingent valuation method. Appl Econ. 1991;23(7):1135-46.

9. Yu X, Gao Z, Zeng Y. Willingness to pay for the "green food" in China. Food Policy. 2014;45:80-7.

10. Dror DM, Radermacher R, Koren R. Willingness to pay for health insurance among rural and poor persons: field evidence from seven micro health insurance units in India. Health policy. 2007:82(1):12-27.

11. Basu R. Willingness-to-pay to prevent Alzheimer's disease: a contingent valuation approach. Int J Health Care Finance Econ. 2013;13(3-4):233-45.

12. Damschroder LJ, Ubel PA, Riis J, Smith DM. An alternative approach for eliciting willingness-to-pay: a randomized internet trial. Judgm Decis Mak. 2007;2(2):96.

13. Shi $L$, Gao Z, Chen $X$. The cross-price effect on willingness-to-pay estimates in open-ended contingent valuation. Food Policy. 2014;46:13-21.

14. Tussupova K, Berndtsson R, Bramryd T, Beisenova R. Investigating willingness to pay to improve water supply services: application of contingent valuation method. Water. 2015;7(6):3024-39.

15. Sousa N, Costa T, Monteiro-Soares M, Rocha Gonçalves F, Azevedo LF. Bias in valuation of health care benefits in metastatic prostate cancer: a contingent valuation of willingness to pay. ASCO Annual Meeting. 2017.

16. Botelho A, Pinto LC. Hypothetical, real, and predicted real willingness to pay in open-ended surveys: experimental results. Appl Econ Lett. 2002;9(15):993-6.

17. Veisten K. Willingness to pay for eco-labelled wood furniture: choice-based conjoint analysis versus open-ended contingent valuation. J For Econ. 2007; 13(1):29-48.

18. Frew EJ, Wolstenholme JL, Whynes DK. Comparing willingness-to-pay: bidding game format versus open-ended and payment scale formats. Health Policy. 2004;68(3):289-98.

19. Lin P-J, Yeh W-S, Neumann PJ. Willingness to pay for a newborn screening test for spinal muscular atrophy. Pediatr Neurol. 2017;66:69-75.

20. Asadi H, Garavand A, Khammarnia M, Abdollahi MB. TheThe sources of work stress among nurses in private hospitals in shiraz, 2016 sources of work stress among nurses in private hospitals in shiraz, 2016. Journal of Health Management and Informatics. 2017:4(3):71-5.

21. Ryan TP. Sample size determination and power: John Wiley \& Sons; 2013.

22. Nord E. The trade-off between severity of illness and treatment effect in cost-value analysis of health care. Health Policy. 1993;24(3):227-38.

23. Breidert C, Hahsler M, Reutterer T. A review of methods for measuring willingness-to-pay. Innovative Marketing. 2006;2(4):8-32.

24. Florax RJ, Travisi CM, Nijkamp P. A meta-analysis of the willingness to pay for reductions in pesticide risk exposure. Eur Rev Agric Econ. 2005;32(4):441-67.

25. Asenso-Okyere WK, Osei-Akoto I, Anum A, Appiah EN. Willingness to pay for health insurance in a developing economy. A pilot study of the informal sector of Ghana using contingent valuation. Health policy. 1997;42(3):223-37.

26. Bärnighausen $T$, Liu Y, Zhang $X$, Sauerborn R. Willingness to pay for social health insurance among informal sector workers in Wuhan, China: a contingent valuation study. BMC Health Serv Res. 2007;7(1):1.

27. Jacobsson F, Carstensen J, Borgquist L. Caring externalities in health economic evaluation: how are they related to severity of illness? Health Policy. 2005;73(2):172-82.

28. Gustafsson-Wright E, Asfaw A, van der Gaag J. Willingness to pay for health insurance: an analysis of the potential market for new low-cost health insurance products in Namibia. Soc Sci Med. 2009;69(9):1351-9.

29. Bustamante AV, Ojeda G, Castañeda X. Willingness to pay for cross-border health insurance between the United States and Mexico. Health Aff. 2008; 27(1):169-78.

30. Hirth RA, Chernew ME, Miller E, Fendrick AM, Weissert WG. Willingness to pay for a quality-adjusted life year in search of a standard. Med Decis Mak. 2000;20(3):332-42

31. Brouwer WB, Niessen LW, Postma MJ, Rutten FF. Need for differential discounting of costs and health effects in cost effectiveness analyses. BMJ. 2005;331 (7514):446-8.

32. Ahmed S, Hoque ME, Sarker AR, Sultana M, Islam Z, Gazi R, et al. Willingness-to-pay for community-based health insurance among informal Workers in Urban Bangladesh. PLoS One. 2016;11(2):e0148211.

33. Krupnick A, Alberini A, Cropper M, Simon N, O'Brien B, Goeree R, et al. Age, health and the willingness to pay for mortality risk reductions: a contingent valuation survey of Ontario residents. J Risk Uncertain. 2002;24(2):161-86.

\section{Submit your manuscript to a SpringerOpen ${ }^{\circ}$ journal and benefit from:}

- Convenient online submission

- Rigorous peer review

- Open access: articles freely available online

- High visibility within the field

- Retaining the copyright to your article

Submit your next manuscript at $\boldsymbol{\nabla}$ springeropen.com 